\title{
Jean Lesaulnier, Images de Port-Royal
}

\section{Monica Pavesio}

\section{(2) OpenEdition}

\section{Journals}

\section{Edizione digitale}

URL: http://journals.openedition.org/studifrancesi/5324

DOI: $10.4000 /$ studifrancesi.5324

ISSN: 2421-5856

\section{Editore}

Rosenberg \& Sellier

\section{Edizione cartacea}

Data di pubblicazione: 1 dicembre 2016

Paginazione: 527

ISSN: 0039-2944

\section{Notizia bibliografica digitale}

Monica Pavesio, "Jean Lesaulnier, Images de Port-Royal », Studi Francesi [Online], 180 (LX | III) | 2016,

online dal 01 janvier 2017, consultato il 18 septembre 2020. URL : http://journals.openedition.org/ studifrancesi/5324; DOI : https://doi.org/10.4000/studifrancesi.5324

\section{Questo documento è stato generato automaticamente il 18 settembre 2020.}

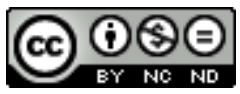

Studi Francesi è distribuita con Licenza Creative Commons Attribuzione - Non commerciale - Non opere derivate 4.0 Internazionale. 


\title{
Jean Lesaulnier, Images de Port-Royal
}

\author{
Monica Pavesio
}

\section{NOTIZIA}

JEAN LESAULNIER, Images de Port-Royal, Tome II, Classiques Garnier, 2015, 543 pp.

1 Il volume di Jean Lesaulnier completa e precisa il precedente, pubblicato nel 2002 con il titolo di Images de Port-Royal I, che ha inaugurato la collezione Univers Port-Royal delle edizioni Classiques Garnier. Seguendo l'esempio del primo tomo, il presente saggio è suddiviso in tre sezioni che raggruppano venticinque studi: «Autour de Port-Royal des Champs» (cap. I-XI), «Questions d'historiographie port-royaliste» (cap. XII-XVII), «Figures discrètes de Port-Royal» (cap. XVIII-XXIV), con in aggiunta, un ultimo capitolo conclusivo intitolato «La modernité de Port-Royal».

2 L'abbazia di Port-Royal des Champs è il luogo - «de communion humaine», secondo le parole di Victor Hugo - in cui si formò e si concretizzò la riforma spirituale della madre Angélique Arnauld che, con uno sparuto numero di giovani monache, fondò il monastero "des Champs", nell'insalubre vallata della Chevreuse e successivamente quello di Parigi. I primi dieci capitoli del volume sono dedicati alla nascita all'inizio del Seicento e al progetto di distruzione del 1693 dell'abbazia "des Champs", ai suoi illustri ospiti, chiamati i "solitari di Port-Royal", dediti alla preghiera, all'educazione dei bambini, studiosi e traduttori della Bibbia, ellenisti e filosofi di grande livello. I sei capitoli successivi si occupano, invece, dei libri stampati a Port-Royal e su Port-Royal, con una ricca sezione dedicata ai manoscritti di Racine, conservati nella biblioteca dell'abbazia, e alle ricerche di Jean-Baptiste e Louis, figli del grande drammaturgo, del famoso Abrégé de l'histoire de Port-Royal, scritto dal padre sulla storia dell'abbazia. I capitoli compresi nella terza parte sono dedicati ad alcune delle personalità di spicco, monache o "solitari" dell'Abbazia, nonché ai rapporti intrattenuti con Port-Royal dai vescovi e dai teologi dell'epoca. Un ultimo capitolo è dedicato alla modernità di questo centro spirituale del Seicento, di quest'abbazia di monache cistercensi divenuta un centro intellettuale d'infinita complessità che gli studi di Jean Lesaulnier ben 
tratteggiano. Una ricca e completa bibliografia, un indice dei nomi e uno dei luoghi completano il volume. 